\title{
Efficacy of a self-applied online program to promote resilience and coping skills in university students in four Spanish- speaking countries: study protocol for a randomized controlled trial
}

\author{
Araceli Palma-Gómez ${ }^{1}$, Rocío Herrero ${ }^{2,3^{*}}$, Rosa Baños ${ }^{2,3}$, Azucena García-Palacios ${ }^{1,2}$, Claudia Castañeiras ${ }^{4}$, \\ Gabriela Lidia Fernandez ${ }^{5}$, Dario Martín Llull4, Lorena Cudris Torres ${ }^{6}$, Libia Alvis Barranco ${ }^{6}$, \\ Leonardo Cárdenas-Gómez ${ }^{7}$ and Cristina Botella ${ }^{1,2}$
}

\begin{abstract}
Background: There is evidence of a high prevalence of depression and anxiety in university students. Therefore, college time is a key period where prevention of mental disorders through interventions that promote resilience and mental health can be relevant. Currently, there are interventions available, but these are insufficient for those who need them. Online interventions are tools that can facilitate global accessibility and are easy for young people to use. CORE (Cultivating Our Resilience) is a self-administered online program, based on Ryff's psychological wellbeing model, to promote resilience and coping skills in university students at risk of developing symptoms of depression or anxiety. The objective is to evaluate the effectiveness of this intervention protocol in comparison with an active control condition targeting healthy lifestyle, and a waiting list control condition. The study will be conducted in four populations of Spanish-speaking university students (Spain, Argentina, Colombia, and Mexico).

Methods: The study design is a randomized controlled trial (RCT). At least 324 university students will be randomly assigned to three conditions: 1) CORE, a 6-week training program to improve resilience; 2) HLP, a 6-week training to promote a healthy lifestyle; and 3) WL, waiting list control condition. The primary outcome measure will be the Connor-Davidson resilience scale. Additionally, measures of anxiety, depression, quality of life and sociodemographic variables (age, sex, incomes, marital status, among others) will be collected. Participants will be evaluated at pre-treatment, after each module, 6 weeks after allocation, and at 3-month follow-up. Intention-to-treat and per-protocol analyses will be performed.

(Continued on next page)
\end{abstract}

\footnotetext{
*Correspondence: rherrero@uji.es; ro.herrero.09@gmail.com

${ }^{2}$ CIBER of Physiopathology of Obesity and Nutrition (CB06/03) Instituto Salud

Carlos III, Madrid, Spain

${ }^{3}$ Universidad de Valencia, Av. Blasco Ibañez, 21, 46021 Valencia, Spain

Full list of author information is available at the end of the article
} 
(Continued from previous page)

Discussion: The results of this study will contribute to research on Internet-administered interventions and the implementation of a protocol that includes a series of components designed to improve resilience and coping skills, increase psychological well-being, and prevent depression and anxiety disorders in Spanish-speaking university students. In addition, avenues will be opened up for new research on the effectiveness of these interventions focused on the prevention and promotion of mental health in Spanish-speaking countries.

Trial registration: Registered at ClinicalTrials.gov NCT03903978 on April 2, 2019.

Keywords: Resilience, Online interventions, Prevention, University students, Mood disorders

\section{Background}

Depression is the leading cause of disability worldwide $[1,2]$; globally, it is estimated that $4.4 \%$ of the population suffer from a depressive disorder, and 3.6\% suffer from an anxiety disorder. According to the data, this prevalence is high in the European region with $12 \%$ for depression and $15 \%$ for anxiety, but even higher in the America with 14 and $21 \%$ respectively, predominantly in women than in men [3].. This impact is associated with lower quality of life and an increased risk of developing serious physical diseases [4], loss of health and functioning, with depression being one of the contributing factors to suicide at ages 15-29 [3, 5]. In light of the magnitude, improving the health of the population is only possible if the countries involved make prevention and treatment a public health priority $[6,7]$.

This preventive work should focus on at-risk populations and developmental stages of the disorders. Some of the most vulnerable stages include adolescence and early adulthood $[8,9]$ These stages correlate with higher rates of depression and anxiety in college students, compared to the adult population, according to data from recent reviews and meta-analyses [10-13].

College life is considered a stage with high stress factors and psychological distress [14, 15]. This vulnerability is associated with various stressors, such as lifestyle changes $[16,17]$ or cultural challenges [18] affecting personal relationships, academic and work performance [19-22], and quality of life related to physical and mental health [23]. These factors may increase the risk of developing a mental disorder [16] or lead to self-harming behaviours and even suicide [21, 24].

The university period is, therefore, a key environment for early detection and prevention of mental illness and increased personal well-being $[13,25]$. A meta-analysis indicates that the interventions with the greatest effect for depression and anxiety in university students are cognitive behavioural therapy (CBT), mindfulness-based interventions and other interventions (such as art, exercise and peer support) [26]. Some studies have found a relationship between high levels of resilience and low levels of emotional disorders such as anxiety, depression, stress, and obsessive-compulsive disorder [27]. One of the preventive approaches to increasing psychological well-being is resilience [28], which promotes protective factors of adaptation to adversity, stress, and the negative effects of exposure to risk situations [29, 30]. These protective factors will moderate and reduce the impact of negative outcomes (such as prevalence of mental disorders) and promote positive outcomes (such as mental health or psychological well-being) [29, 31].

Based on this approach, several studies have demonstrated the effectiveness of resilience interventions in reducing depressive or anxious symptoms in youth, adolescents [32-35], and university students [36]. In addition, promoting resilience has been shown to be most effective with cognitive-behavioural interventions [32] combined with mindfulness techniques [37], improving personal relationships [38], coping strategies [39], and physical exercise [40] As a meta-analysis shows, work on protective factors rather than on other variables has a greater effect on promoting resilience [41]. However, there is still no empirically validated theoretical framework describing the mode of action of resilience interventions, and so it is important to study interventions that promote resilience and prevent stressrelated mental health problems [42-44].

There are other lines of research focused on the prevention of mild or moderate depressive symptoms called lowintensity psychological interventions [45-47]. One of these interventions is the promotion of Healthy Lifestyles, which shows significant clinical benefits by promoting physical health, diet, and sleep control to reduce depressive symptoms [48], and it has also been proposed for interventions in college students to prevent risk behaviours [49-51]. Although this approach regulates risk behaviours, it can be an important factor in preventing emotional disturbance, and it can be compared to resilience-based interventions.

An effective technological tool for carrying out preventive and treatment interventions in mental health is the use of the Internet [52-55]. In Europe, 79\% of the population between the ages of 16 and 74 use the Internet [56], and in Latin America and the Caribbean, 55\% [57]. Mainly young people are immersed in the digital world, making the Internet an effective and efficient tool 
[58]. The Internet is, therefore, a valuable resource for implementing empirically validated prevention programs in different regions such as Europe and Latin America, which would reduce costs by facilitating access and meeting preventive mental health objectives in at-risk populations, as established by the World Health Organization [7].

Internet-based cognitive-behavioural treatments aimed at university students have been effective in reducing psychological stress, anxiety, and depression [59-61]. A meta-analysis points to this type of intervention as a feasible method to reach this population [62], and intervention protocols to promote resilience in university students have been published [36]. Internet-based interventions $[63,64]$ overcome barriers such as cost, availability of services, waiting time, access, and stigma. In addition, the same effectiveness has been demonstrated as in face-toface interventions [65-68], whether or not they are preceded by a minimum amount of therapeutic care or with other mental health professionals [69-74], Thus, it is a feasible method for the prevention of mental disorders [75-77] and the promotion of healthy behaviours [58].

Online intervention is a growing field, given the increasing rates of access to technologies to people, the reducing on cost, and the potential advantages that this way of dispense the intervention provides (e.i. the scalability, overcoming geographical barriers, increasing in flexibility on time schedule ...). Studies testing this kind of approach have been mainly conducting in developed countries with high or upper-middle incomes. Lately, efforts on testing the interventions in developing countries have been done. Protocols developed or validated on Western countries started to be adapted and tested [7881] with different methodologies [82]. The evidence on the effects in countries with middle or low income are promising $[79,83,84]$, but is still scarce [85]. One potential gap is the lack of resources to properly develop, adapt, and test the interventions. In this sense, the widespread use of Spanish language provides an opportunity to test already validated interventions in other countries with the need of minor changes. Therefore, the objective of the study is to test the effectiveness of an Internetbased preventive program to promote resilience and coping skills in college students at risk of developing emotional disorders in Spanish-speaking countries: Spain, Argentina, Colombia, and Mexico, compared to a healthy lifestyle program and a waiting list control group. The hypotheses are that the CORE program will improve the resilience, coping skills, and psychological well-being of college students. In addition, CORE and active control of Healthy Lifestyle are expected to be more effective than the Waiting List control group, but with greater and statistically significant effects of CORE as an intervention that is targeting to promote resilience.

\section{Methods/design \\ Study design}

A three-armed, single blind, randomized controlled trial (RCT) with repeated measurements at three times (at baseline, 6 weeks, and 3 months follow up) will be conducted in four Spanish-speaking countries (Spain, Argentina, Colombia, and Mexico). Due to the nature of the study, the condition will be notified to participants of to which they have been assigned, but those allocated to the intervention groups will remain unaware of the type of intervention they will receive. Participants who meet the inclusion criteria will be randomized to one of the three study arms in a 1:1:1 ratio: 1) unguided internet-based resilience intervention (CORE); 2) unguided healthy lifestyle program (HLP); and 3) Waiting list control (WL). Participants allocated to the WL condition will receive access to the intervention once they have completed the evaluation period.

The study has been approved by the Ethics Committee of University Jaume I in Spain, it was registered with the trial code NCT03903978, and it will be conducted in accordance with the CONSORT 2010 statement [86, 87], the CONSORT-EHEALTH guidelines [88], and the SPIRIT guidelines [89]. Figure 1 shows the study design.

\section{Sample size calculation}

The primary outcome is the change in the resilience levels from baseline to post-intervention. Therefore, the Connor-Davidson Resilience Scale (CD-RISC) scores will be compared before and after the intervention in the CORE, HTP, and WL groups to obtain information about the normality of the CD-RISC scores within the target population. So far, there are no data on the effect size obtained for Internet-based interventions to promote resilience. However, a recent meta-analysis [37] compared the effectiveness of psychotherapy as an outcome for improving resilience in mental health and psychological well-being, and the authors found a moderate positive effect of resilience interventions $(0.44,95 \%$ CI 0.23 to 0.64$)$. Considering these findings, the sample size was calculated with a significance level of 0.05 , for a potency of 0.80 . We take a conservative approach, we assume an effect of 0.5 (Hedges' g), which, according to Cohen [90], can be considered a medium magnitude effect. Since our design included three experimental conditions (CORE, HLP, WL), one-way ANOVA was assumed for the statistical analyses. The total sample size calculated is 249 Estimating a potential dropout rate of $30 \%$, the total sample size was determined to be 324 , requiring 108 subjects in each condition [91].

\section{Study population}

The participants will be college students from Spain, Argentina, Colombia, and Mexico who score low on levels of resilience (-1SD) according to the primary outcome measure. 


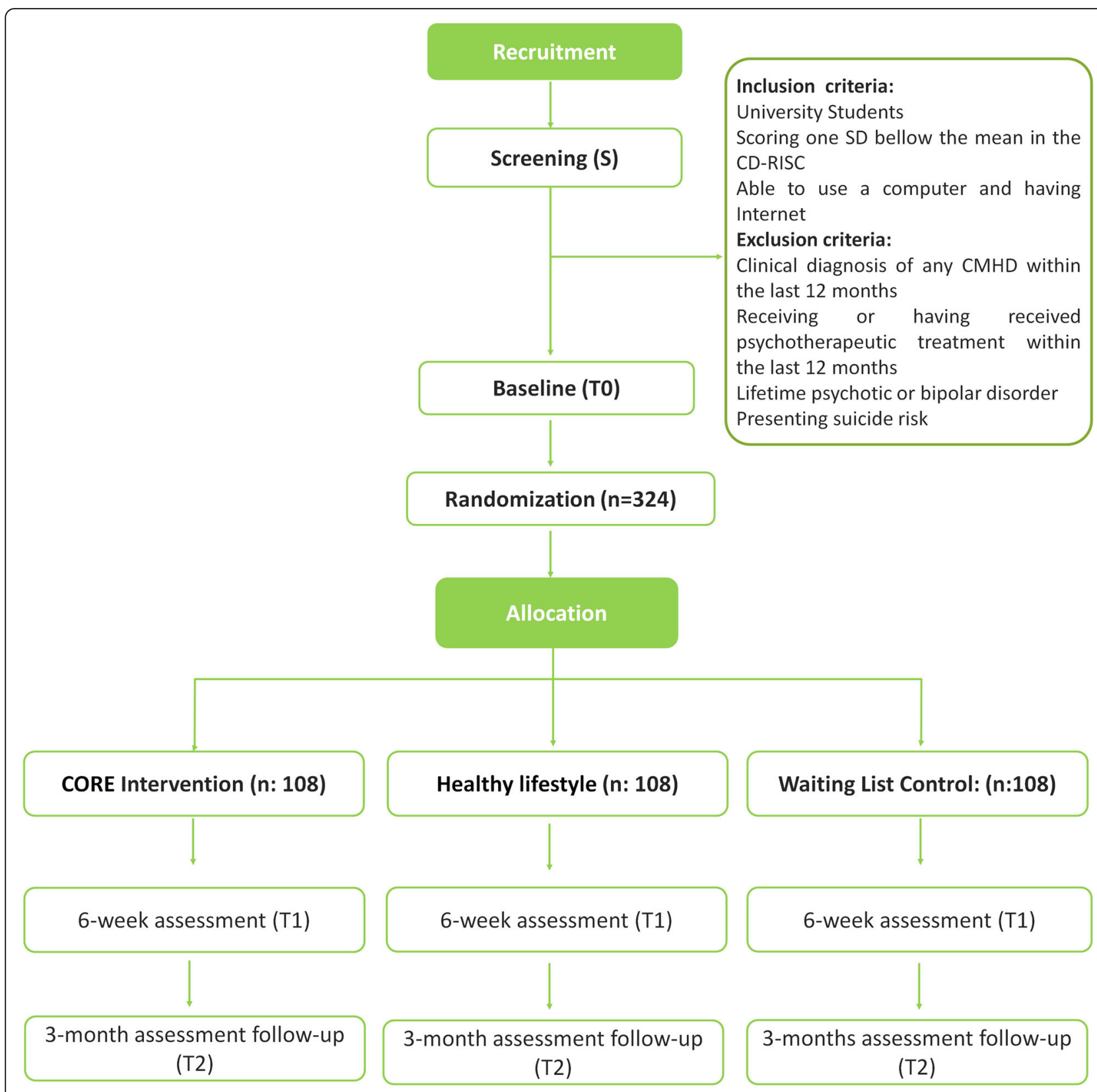

Fig. 1 Study flowchart

\section{Eligibility criteria}

Inclusion criteria will include the following: a) College students with a standard deviation score below the sample mean on the Connor-Davidson Resilience Scale (CDRISC-25). b) Adequate knowledge to understand and read and/or speak Spanish. (c) Internet access and computer skills.

Exclusion criteria include the following, college students: a) with a CMHD record in the past 12 months; b) who are or have been undergoing psychotherapy in the past 12 months; c) with a current or past psychotic or bipolar disorder; d) at risk of suicide.
Participants who do not meet the inclusion criteria will be provided with alternative interventions that are appropriate for their needs.

\section{Recruitment}

Five universities in Latin America and two in Spain were contacted. These partners contributed to the management of the ethical procedures in each of the countries and to the review of the procedures and contents of the interventions. The study will be announced on the official websites and e-mail addresses of the universities: Universitat Jaume I, Castellón, Spain, https://www.uji. 
es/; Universitat de Valencia, Spain, http://www.uv.es/; Universidad de Buenos Aires, http://www.uba.ar/; Universidad Nacional de Mar del Plata, Argentina, http:// www.mdp.edu.ar/; Universidad Autónoma del Estado de Hidalgo, Mexico, https://www.uaeh.edu.mx/; Universidad Politécnica de Tecámac, México, http://uptecamac. edomex.gob.mx/; and Universidad Popular del Cesar, Colombia, https://www.unicesar.edu.co/. It will also be communicated through public spaces such as student social networks (e.g. Facebook, Instagram, and Twitter), posters, and newspaper advertisements. Interested students will request participation by email. A link with the informed consent and the screening criteria will be sent in reply.

\section{Interventions}

\section{Intervention (CORE)}

CORE is a program developed within the framework of the ICare Project (H2020 No. 634757), and good results were obtain in a previous study conducted in Spain, Germany, and Switzerland [63]. This program is a prevention protocol with therapeutic components based on empirical evidence following the Ryff wellbeing model $[86,92]$ and organized in six dimensions: autonomy, self-acceptance, mastery of the environment, purpose in life, positive relationships, and personal growth. The main objective is to teach coping skills and strategies to cope with stressful everyday situations in order to improve resilience, promote self-efficacy, and increase wellbeing. The intervention consists of six interactive modules designed for weekly sessions (see Table 1), and it includes exercises to practice the skills proposed in each module. CORE is a program designing to increase resilience following Ryff wellbeing model $[86,92]$, therefore along the use of the program the participant will be.

Users will be recommended to perform one module per week, which will be automatically activated on the platform, Participants will have a total of 6 weeks to complete the program prior the activation of post assessment, were the modules will remain active. Post assessment and 3 months follow-up will be automatically activated by the platform. Participants can leave the intervention at any time. Once the post-treatment assessment has been completed they will have free access during the next 3 months, either to enter and use the unfinished modules or for revisit them at any occasion. The system will track any access to the content. The intervention has a series of task and homework to assist the participant in the acquisition or development of the proposed skill. Tasks and homework are proposed along the intervention and their fulfilment are tracked by the system.

The program was financiered and developed within the ICare project (H2020 No. 634757). Pilot studies and focus groups with college students and health professionals were carried out for its development. It was adapted to the web format, adding multimedia material (videos, audio, and images), and verification questions (see Fig. 2). Previous data on acceptability shows good rates among users. Currently, the preliminary results on

Table 1 CORE modules and their objectives

\begin{tabular}{|c|c|}
\hline Module & Objective \\
\hline 0. Welcome & Introduction module to the program, with an explanation about the tools and the way to use CORE \\
\hline 1. Psychoeducation & $\begin{array}{l}\text { Explanation of psychological wellbeing and the concept of resilience: } \\
\text { - Understand the concept of psychological well-being, its most important aspects, and their relevance in life. } \\
\text { - Understand the concept of resilience and the importance of training and cultivating it. }\end{array}$ \\
\hline 2. Autonomy: building my way & $\begin{array}{l}\text { Enhancement of autonomy: } \\
\text { - Develop a healthy lifestyle (by pursuing balance in several areas: activity, food, sleep). This lifestyle } \\
\text { will allow the person to focus on his/her goals in life. } \\
\text { - Increase psychological well-being by working on abilities potentially related to values and goals in life. }\end{array}$ \\
\hline 3. Mindfulness and self-compassion & $\begin{array}{l}\text { Training in mindfulness, savoring, and an attitude of self-compassion: } \\
\text { - Learn the meaning of "mindfulness", how to develop this ability, and the benefits that its practice can bring } \\
\text { - Learn to distance ourselves from our thoughts and how to handle them. } \\
\text { - Understand the importance of, recognize, capture, and enjoy the good moments. } \\
\text { - Develop the skill of kindness and self-care, i.e., the capacity for self-compassion. }\end{array}$ \\
\hline 4. Overcoming obstacles & $\begin{array}{l}\text { Development of coping strategies to deal with daily difficulties in life: } \\
\text { - Be aware of the importance of facing problems properly. } \\
\text { - Learn the Problem Solving Technique and how to apply it. } \\
\text { - Learn the role of our thoughts in the way we feel and how to be flexible in our way of } \\
\text { interpreting situations. }\end{array}$ \\
\hline 5. Connecting to others & $\begin{array}{l}\text { Acknowledge the relevance of relationships and how they can be helpful in the construction of well-being: } \\
\text { - Recognize the importance of our social relations. } \\
\text { - Learn to care for and improve our social relations. } \\
\text { - Learn to promote quality relationships, which can contribute to maintaining and strengthening resilience. }\end{array}$ \\
\hline
\end{tabular}

6. Purpose in life and personal growth Encourage students to deal with the future with a positive attitude, taking into account what is important for each person and planning the future according to these objectives. 


\section{Psychology \& Technology}

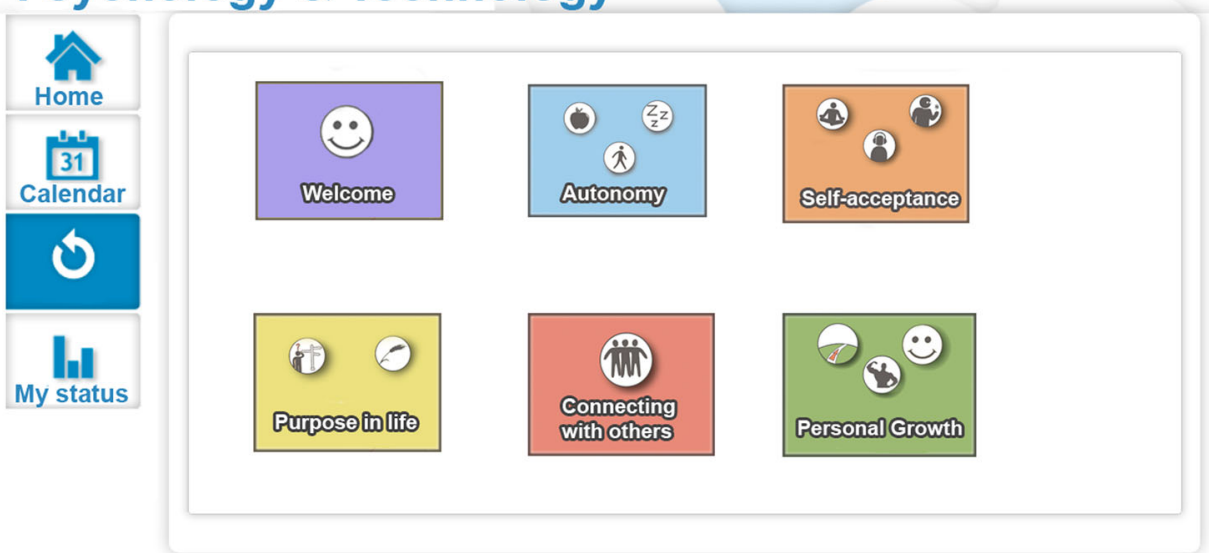

\section{Psychology \& Technology}

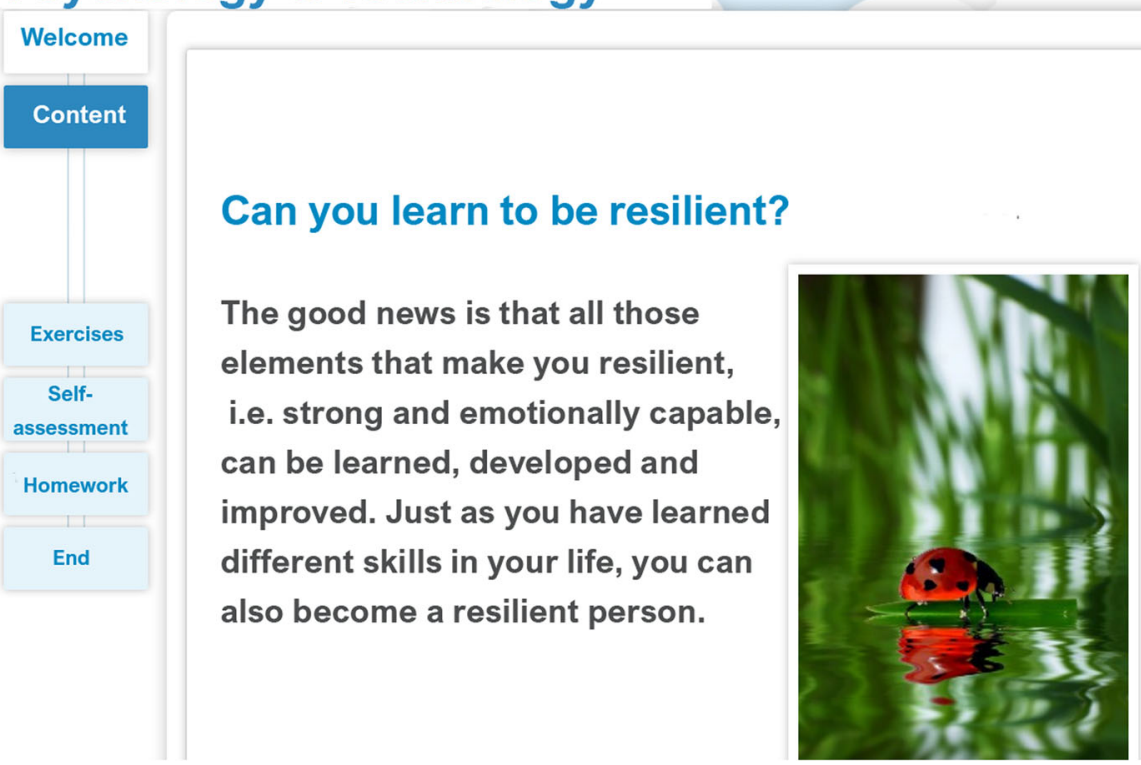

Fig. 2 CORE training: multimedia tools within the platform: https://www.psicologiaytecnologia.com/

effectiveness are good. In addition to the content the participants receives weekly support messages with general information regarding the tasks participant must work during the week. These messages will be included in both active conditions (CORE, HLP), and are predesigned (see Table 2).

All modules have a common structure, starting with a scheme of the most relevant points to work during the session, followed by the content itself. At the end of the module, exercises and self-test questionnaire are presented to verify whether the explanation has been understood and provide feedback either if the answer is correct or not. In addition, at the beginning of each module, a verification test is provide to see the degree of adherence to the tasks proposed. CORE has as main goal to impact on the resilience and wellbeing of participants. To do so the intervention content of 6 interactive modules. In the first module the participant receive an 
Table 2 Example of the e-mail support protocol per module for the follow-up of the participants

\begin{tabular}{|c|c|}
\hline Module/subject & Message \\
\hline $\begin{array}{l}\text { 1.1 Session } 1 \text { - First week } \\
\text { reminder } \\
\text { Subject: CORE - Module } 1\end{array}$ & $\begin{array}{l}\text { Dear } X \text {, / Session } 1 \text { is available for you! / } \\
\text { We want to invite you to take the time } \\
\text { to do the training. The training can give } \\
\text { you helpful ideas, especially when you } \\
\text { are very stressed with your daily life. It } \\
\text { will help you to live a more relaxed } \\
\text { and aware life. / We would be happy } \\
\text { to hear from you soon and wish you } \\
\text { all the best. / Best wishes } / Y \text { from the } \\
\text { CORE-Team }\end{array}$ \\
\hline $\begin{array}{l}1.2 \text { Session } 1 \text { - Second week } \\
\text { reminder } \\
\text { Subject: CORE - Module } 1\end{array}$ & $\begin{array}{l}\text { Dear X, We know that it isn't always } \\
\text { easy to integrate the training into } \\
\text { your daily life, particularly when you } \\
\text { have a lot of other commitments. } \\
\text { Nonetheless, we want to encourage } \\
\text { you to find some time to work on } \\
\text { the training. / In session one, you } \\
\text { learn what it means to be resilient, } \\
\text { and you get useful tips that can } \\
\text { help you to become more resilient. } \\
\text { / We would be glad to hear back } \\
\text { from you shortly. / Best wishes / } \\
Y \text { from the CORE-Team }\end{array}$ \\
\hline $\begin{array}{l}1.3 \text { Session } 1 \text { - Third week } \\
\text { reminder } \\
\text { Subject: CORE - Module } 1\end{array}$ & $\begin{array}{l}\text { Dear } X, \text { / Please think about this: } \\
\text { To profit from the training, it is } \\
\text { important, to stay on track. } \\
\text { Therefore, it is not only important } \\
\text { to integrate the exercises into your } \\
\text { daily life, but also to work on your } \\
\text { next session. We also want to } \\
\text { encourage you to find some time } \\
\text { to do the first session to improve } \\
\text { your well-being actively. / If you } \\
\text { have any questions, don't hesitate } \\
\text { to contact us. } \\
\text { Best regards / Y from the CORE-Team }\end{array}$ \\
\hline
\end{tabular}

explanation of psychological wellbeing and resilience and the importance of training and cultivating it. The second module is focus on the development of a healthy. The third module is aimed to train mindfulness, savouring, and an attitude of kindness and self-compassion. On the fourth module the objective is to give information on how to overcome obstacles by learning the Problem Solving Technique. On the fifth module, participants will be instructed in the relevance of relationships and how they can be helpful in the construction of well-being. Participants will be taught about the ways to promote quality relationships. In the last module participants will be encourage to have a positive attitude toward the future, focusing on what is important for each person and planning the future in accordance.

CORE will operate on the web platform: Psychology and Technology (https://www.psicologiaytecnologia.labpsitec.es/). The platform allows researchers to produce the content of the intervention and deliver it to the participants. It also ensures secure and encrypted communication between clients and the researcher. Given that the study will be conducted
Table 3 HLP healthy lifestyle and their objectives

\begin{tabular}{|c|c|}
\hline Module & Objective \\
\hline 1. Beginning to change lifestyle & $\begin{array}{l}\text { Learn to identify healthy behaviors } \\
\text { and risks in order to recognize } \\
\text { obstacles that impede adopting } \\
\text { a healthy lifestyle. Teach hygiene } \\
\text { and eating strategies to improve } \\
\text { emotional health and well-being. }\end{array}$ \\
\hline 2. Learning to feed ourselves & $\begin{array}{l}\text { Teach the importance of a } \\
\text { balanced diet in maintaining } \\
\text { good physical and mental health. } \\
\text { The Mediterranean diet will be } \\
\text { taken as an example of a balanced } \\
\text { diet. Obstacles to maintaining a } \\
\text { healthy diet will be analyzed to } \\
\text { prevent any depressive symptoms. }\end{array}$ \\
\hline 3. Moving our body & $\begin{array}{l}\text { The importance of "moving" and } \\
\text { activating behavior will be taught } \\
\text { through regular exercise routines } \\
\text { to improve mood. Training will be } \\
\text { provided to increase motivation, } \\
\text { activity, and fitness. }\end{array}$ \\
\hline 4. The importance of good sleep & $\begin{array}{l}\text { Strategies will be provided to } \\
\text { understand the relationship between } \\
\text { sleep and overall health, emphasizing } \\
\text { the importance of good sleep in } \\
\text { maintaining a good mood. }\end{array}$ \\
\hline
\end{tabular}

in different countries and the intervention is self-apply, user guidelines for researchers and end users were made. The guidelines content information about the ways to access the platform, common questions, and a support protocol for researchers. Beside the platform counts with a support system, that provides help on technical issues to users.

The content of the program and messages was reviewed by researchers from Latin American countries, and it was tested in small pilot study in each country. The content was considered adequate, and small changes were made in the wording.

\section{Healthy lifestyle program (HLP)}

HLP is a Healthy Lifestyle Program was developed under the framework of a national project in Spain funded by Carlos III Institute. The program has been tested and showed to be effective in reducing depressive symptoms in patients with mild to moderate depression. Its background supports its usefulness for improving the person's lifestyle and reduce depressive symptoms. The psychoeducation components are based on the protocol of low-intensity psycho-pedagogical intervention for depression applied by ICT models $[93,94]$ for mild or moderate depressive symptoms in primary care [45-47] and the prevention of depressive symptoms [95], whose components have been shown to be effective [94]. HPL is a program that provides information to promote a healthy physical and mental lifestyle regarding topics related to physical activity, diet, and sleep management (see Table 3). The 
intervention consists of four interactive modules designed as weekly sessions, and it includes multimedia elements: videos, audios, vignettes and images.

The whole program has a common structure for all modules. Each module starts with a scheme of the most relevant points to work during the session, followed by the content itself. At the end of the module, different exercises are proposed, and self-test questionnaire is presented to verify whether the explanation has been understood and provide feedback either if the answer is correct or not. In addition, before starting each module, a verification test is provide to see whether the participants have carried out the proposed tasks and responds by congratulating them or encouraging them to do the task. HLP has as main goal to impact on the life style of participants. Therefore the content gives information regarding the relation between a healthy life style and wellbeing, the importance of carry out regular physical activity. Advices regarding diet are provided, giving information about the Mediterranean diet, along with education on 6 healthy dietary commands. All of this will come with information and practical exercises on how to systematize food and activity-related behaviours. In addition, the importance of developing a social support network will be emphasized. People will be shown specific techniques on how to create and maintain an adequate social support network.

Participants will have a total of 6 weeks to complete the program prior the activation of post assessment. Post assessment and 3 months follow-up will be automatically activated by the platform. Participants can leave the intervention at any time. Once the post-treatment assessment has been completed they will have free access during the next 3 months, either to enter and use the unfinished modules or for revisit them at any occasion. The system will track any access to the content. The intervention content a series of task and homework to assist the participant in the acquisition or development of the proposed skill. Tasks and homework are tracked by the system.

The program was financiered and developed within the Carlos III Institute. Pilot studies and focus groups were carried out for its development. It was adapted to the web format, adding multimedia material (videos, audio, and images), and verification questions. Currently, the preliminary results on effectiveness are good. In addition to the content and in order provide the same support that in CORE condition; the participants will receive weekly support messages with general information regarding the tasks participant must work during the week.

HLP has been manualized and adapted for the web, and it will be use on the web platform Psychology and Technology. The procedures for its use will follow the same structure than in CORE condition.

The content of the program and messages was reviewed by researchers from Latin American countries, and it was tested in small pilot study in each country. The content

Table 4 Study measures, time and type of assessment

\begin{tabular}{|c|c|c|c|c|c|c|}
\hline Questionnaire & Construct & $\begin{array}{l}\text { SCREENING } \\
\text { (S) }\end{array}$ & $\begin{array}{l}\text { PRE } \\
\text { (T0) }\end{array}$ & $\begin{array}{l}\text { PRE-POST } \\
\text { MODULES }\end{array}$ & $\begin{array}{l}\text { POST } \\
\text { (8 weeks) } \\
\text { (T1) }\end{array}$ & $\begin{array}{l}\text { FU } \\
\text { (6 months) } \\
\text { (T2) } \\
\end{array}$ \\
\hline Socio-demographic data & Demographics & $x$ & - & - & - & - \\
\hline CD-RISC - 25 & Resilience (primary outcome) & $x$ & $x$ & - & $x$ & $x$ \\
\hline ODSIS & $\begin{array}{l}\text { Overall Depression Severity and } \\
\text { Impairment Scale }\end{array}$ & - & $x$ & $x$ & $x$ & - \\
\hline Suicidal ideation & Risk of suicide & - & $x$ & $x$ & $x$ & - \\
\hline PHQ-9 & Depression severity & $x$ & $x$ & - & $x$ & $x$ \\
\hline $\mathrm{BFI}-10$ & Personality inventory & - & $x$ & - & - & - \\
\hline GAD-7 & Anxiety symptoms & - & $x$ & - & $x$ & $x$ \\
\hline EAHF & Openness to the future scale & - & $x$ & & $x$ & $x$ \\
\hline CSQ & Treatment satisfaction & - & - & - & $x$ & - \\
\hline PANAS & Positive and negative affect & - & $x$ & - & $x$ & $x$ \\
\hline PWBS-29 & Psychological well-being & - & $x$ & - & $x$ & $x$ \\
\hline SCS-SF & Self-compassion & - & $x$ & - & $x$ & $x$ \\
\hline RPA & Response to positive affect & - & $x$ & - & $x$ & $x$ \\
\hline PSS-4 & Perceived stress & - & $x$ & - & $x$ & $x$ \\
\hline OASIS & Overall Anxiety Severity and Impairment Scale & - & $x$ & $x$ & $x$ & - \\
\hline CEQ & Credibility and expectancy of treatment & - & $x$ & - & - & - \\
\hline WAI-TECH & Therapeutic alliance & - & - & - & $x$ & - \\
\hline
\end{tabular}


was considered adequate, and small changes were made in the wording.

\section{Waiting list (WL)}

Participants assigned to the Waiting List Control condition will be evaluated and monitored prior to the beginning of the intervention, at 6 weeks, and in a follow-up at 3 months. After the last evaluation, they will receive access to the CORE intervention.

\section{Outcomes}

All the assessments will be conducted online in each country using the Psychology and Technology platform. Table 4 provides an overview of the measures and their time of assessment.

\section{Primary outcome \\ Resilience}

Connor-Davidson's Resilience Scale (CDRISC) [96] assesses stress coping skills using a 25-item self-report questionnaire that uses a five-point Likert scale ranging from 0 to $4 \quad(0=$ strongly disagree, $4=$ strongly agree $)$. Scores range from 0 to 100 , with higher scores reflecting greater resilience. Previous studies show that it has good internal consistency (Cronbach alpha above 0.70) [97-100].

\section{Secondary outcomes \\ Well-being}

The Ryff Scales of Psychological Well-Being - 29 items (PWBS-29) [86] is an instrument for measuring the faces of psychological well-being, including the six dimensions of the Ryff model (autonomy, self-acceptance, mastery of the environment, personal growth, positive relationships with others, and purpose in life). Response scores range from 1 to 6 ( $1=$ strongly disagree, $6=$ strongly agree) . This scale has been shown to have good psychometric properties [87, 88].

\section{Positive and negative emotionality}

Positive and Negative Effects Program (PANAS) [89]. PANAS evaluates two independent dimensions: positive affect (PANAS+) and negative affect (PANAS-). It consists of 20 items divided into two dimensions with 10 items each, with scores ranging from 10 to 50. It has shown good properties of validity, convergence, and divergence, and it is a brief, reliable self-report measure [101].

The Responses to Positive Affect questionnaire (RPA) [102] is a questionnaire that assesses the responses to positive affective states and consists of 17 items. Items are rated on a four-point scale, ranging from 1 (almost never) to 4 (almost always). The original measure consists of three factor-analytically derived subscales: Dampening, Self-focused positive rumination, and Emotionfocused positive rumination. Initial psychometric results with the original English version show adequate reliability, validity, and internal consistency for each scale $(\alpha=$ 0.76, 0.72, 0.73 for Factors I: Emotion-focus -III: Selffocus, respectively) [102]. Discriminant validity has been supported because the scale is uniquely related to risk of hypomania after controlling for other measures of impulsivity and responses to positive affect [103].

Openness to the Future Scale (OFS) [104] consists of 10 items with scores ranging from 1 to 5 on a Likert scale. It assesses expectations and positive affectivity towards the future, which includes five domains: (1) Illusion of control, (2) Acceptance, (3) Commitment to life and planning, (4) Positive orientation towards the future, and (5) Self-efficacy towards the future. The Openness to the Future scale shows similarly good convergent and discriminant validity across clinical and community samples. Cronbach alphas for the 10-item scale were acceptable for both the clinical (.82) and community samples (.87), with cut-off points from 37.5 to 38 .

\section{Depression and anxiety}

The Patient Health Questionnaire (PHQ-9) [105] is used to examine and diagnose patients with depressive disorders. It consists of nine-items measured on a scale from 0 to $3(0=$ not at all, $3=$ almost every day). Total scores range from 0 to 27 . The severity cut-off points for depression are $5,10,15$, and 20 , and they represent, respectively, the thresholds for mild, moderate, moderately severe, and severe depression. The PHQ-9 has been shown to have good psychometric properties [106].

Overall Depression Severity and Impairment Scale (ODSIS) [107]. It is a self-report measure with five-items that assess experiences related to depression, measuring its frequency and severity, as well as the level of avoidance behaviours, interference with work, school, and home, and associated social interference. The internal consistency of the scale has been shown to be excellent, with Cronbach alphas between 0.91 and 0.94 and good convergent and discriminant validity [108].

Overall Anxiety Severity and Impairment Scale (OASIS) [109]. It is a five-item questionnaire, with items rated from 0 to 4 that evaluate the frequency and severity of anxiety symptoms. The instrument also provides measures related to anxiety symptoms, such as avoidance, work, academy, social, and daily life disabilities. According to a psychometric analysis, it has good internal consistency $(\alpha=.80)$, test-test reliability $(\mathrm{k}=.82)$, and convergent validity. Online adaptation to a Spanish sample shows good internal consistency $(\alpha=0.86)$, adequate convergent and discriminant validity, and a cut-off score of 7.5 [108, 110].

The Generalized Anxiety Disorder Questionnaire (GAD-7) [111] It is a seven-item dimensional self-administration scale designed to assess the presence of the symptoms of Generalized Anxiety Disorder (GAD) according to the 
DSM-IV. It is a one-dimensional self-administered scale, and although it does not provide a definitive diagnosis of $\mathrm{GAD}$, it is an efficient, quick to apply, reliable, and valid instrument for detecting symptoms of an anxiety disorder. The scoring scale ranges from 0 to $3(0=$ nothing, $3=$ almost every day), adding up to 0 to 21 points. There are four severity cut-off points (minimum $=0$ to 4 , mild $=5$ to 9 , moderate $=10$ to 14 , serious $=14$ to 20 ) representing minimum to severe general anxiety thresholds. The GAD-7 has demonstrated good internal consistency and test-retest reliability, as well as convergent, construction, criterion, procedural, and factorial validity for GAD diagnosis [111-113].

The Perceived Stress Scale - 4 items (PSS-4) [114] It is a four-item self-report questionnaire that assesses the extent to which recent life situations are considered stressful. It uses a Likert scale from 1 to 5 ( 1 = never, $5=$ very often). The PSS-4 is a short version that has been used for telephone interviews or study conditions requiring short versions [115]. It has demonstrated good internal consistency reliability in different studies $[115,116]$.

\section{Self-compassion}

Self-compassion Scale - Short Form (SCS-SF) [117] is designed to assess general self-compassion (total score) and three facets of this construct: common humanity (SCSCH), mindfulness (SCS-M), and self-kindness (SCS-SK). This version is shorter than the original version of the 26-item SCS [118]. It contains 6 subscales representing positive and negative aspects of each facet. A five-point Likert-type scale is used, ranging from 1 to 5 ( $1=$ almost never, $5=$ almost always $)$. This short version (SCS-SF) has been shown to be valid and reliable [117].

\section{Personality}

10-Item Big Five Inventory (BFI-10) [119] was developed to provide a personality inventory for research environments with extreme time constraints. This questionnaire is an abridged version of the 44-item BFI [120]. It uses a five-point scale ranging from 1 to 5 ( $1=$ strongly disagree, $5=$ strongly agree). Previous studies have shown that this version has psychometric properties that are comparable in size and structure to those of the full BFI scale [119].

\section{Program evaluation}

The Credibility and Expectancy Questionnaire (CEQ) [121] evaluates factors of patient expectations and credibility of the treatment. This self-report consists of sixitems with responses rated on a 10-point scale and on a scale of $1-100 \%$. These factors have been shown to be stable in different populations, with high internal consistency within each factor [121].
Client Satisfaction Questionnaire (CSQ) [122, 123] consists of eight-items measured on a 4-point scale, with total scores ranging from 8 to 32 measuring the overall level of patient satisfaction with the treatment. Studies show good internal consistency reliability [122-125].

Working Alliance Inventory for Technology Based Interventions (WAI-TECH) [126] is a questionnaire that evaluates the therapeutic alliance between the technological tool and the patient. It covers two dimensions of the working alliance: (1) therapeutic objectives and (2) tasks. It consists of 8 items rated on a 5 -point Likert scale ranging from 1 to 5 ( 1 = never, 5 = always). This questionnaire maintains adequate reliability and validity [126].

\section{Other measures}

Measurements of sociodemographic variables are included: age, sex, household size and income, marital status, employment status, total population of the place of residence, nationality, level of education, and living situation. In addition, health-related variables will be measured: presence of psychological disorders (past and present) and whether treatment is currently being carried out.

Dropouts, the participants will be asked about their reasons for cancelling the intervention.

\section{Support}

Each country will provide their supporters, which will have at least a Bachelor's degree in Psychology. All supporters will received a training in the protocol via an online platform coordinated by the Spanish team. The training consist in 2 days session and last $2 \mathrm{~h}$ each. On the first session, information about the overall goal of the study, conditions and time schedule will be explain. The documentation with the procedure explained by steps will be share and doubts on how to proceed will be solve. Second day will be dedicated on the use of the platform, supporters will be requested to create accounts, assign interventions, among other task they must know how to do given will be required for the trial. All supporters will in addition had a contact information to solve any doubt or problem they can found either in the trial or with the use of the platform.

\section{Statistical analysis}

Intention-to-treat analysis and analysis per protocol will be carried out according to CONSORT recommendations [127]. The three groups at baseline will be compared to verify that there are no significant differences between them and, therefore, to confirm that they are comparable after randomization. One-way ANOVAs will be used for continuous variables and Chi-square tests of independence for categorical variables. For continuous outcome measures in the post-test, the assumption of 
homoscedasticity will be evaluated with the Levene test. If this assumption is met, the usual F-test will be applied for all three groups to compare post-test means. When the assumption of homoscedasticity is not met, BrownForsythe F test will be applied. Statistically significant Ftests will be followed by post hoc comparisons. In addition, Tukey procedure, will be applied when the assumption of homoscedasticity is met, and the GamesHowell procedure if it is not.

The intention-to-treat principle will be used to analyse primary and secondary post-treatment outcomes and at 3month follow-up, using mixed-effect models with a maximum likelihood estimate of complete information, to properly evaluate data missing from repeated ANOVA measurements [128]. The results of the ANOVA and post-hoc comparisons were supplemented by calculating effect sizes using Cohen's standardized mean difference [90]. The effect sizes will be calculated to compare both changes within a group and between groups, all based on a combined standard deviation. Per protocol analysis (completers) will be carried out to help draw conclusions about maximum treatment efficacy [129].

When the trial is completed, the analytical methodology of the RCT will be reviewed to select the most appropriate analytical procedures prior to data analysis.

\section{Discussion}

This paper describes an Internet-based protocol designed to promote resilience and coping skills among college students in Spanish-speaking countries (Spain, Argentina, Colombia, and Mexico). The content is based primarily on Carol Ryff's model of psychological wellbeing $[86,92,130,131]$. Our goal is to evaluate the effectiveness, understood as acceptance of the program in particular and of Internet-based interventions in general, compared to an active control condition (HPL) and a waiting list (WL), using five universities -armed system.

There is a high prevalence of emotional disorders among young people around the world [132], and therefore it is essential to create preventive interventions in these populations at risk of developing a mental disorder $[74,133-135]$ such as the college population $[10,11]$. This evidence suggests shifting attention to vulnerable populations and generating intervention strategies that include intervention planning, evaluation, and even effective health policies [136], reducing the costs of disability globally, creating strategic plans for improving quality of life, and building supportive environments and resilient communities [137].

Hence, the college is a key environment for the early detection and prevention of mental illnesses that may have high future economic costs [138]. Promoting resilience is an approach that supports this goal and wellbeing in this stage of life [139]. Given the importance of developing preventive interventions that promote resilience in at-risk populations, such as college students, it is important to propose interventions that are affordable and accessible to all. The Internet can be an effective means of delivering mental health interventions. This alternative format to traditional face-to-face psychological programs will increase the accessibility of psychological interventions for college students and will increase the tools of professionals to reach a greater number of people (following the recommendations of the National Institute of Mental Health Psychosocial Intervention Development Workgroup and the New Freedom Commission on Mental Health) [140, 141]. College students are immersed in digital worlds, and so Internet-based interventions can be potentially advantageous compared to face-to-face interventions [55]. Even though in Europe interventions for the prevention of depression and the promotion of resilience have already been established $[142,143]$, there are no studies that show results in college students of implementing technological tools such as the Internet for delivering psychological interventions.

Consequently, the strengths of this study focus on two aspects: First, to our knowledge, this would be the first RCT to evaluate an online intervention to improve the resilience of Spanish-speaking college students (in Spain and Latin America). Second, CORE is a three-armed, single blind multi-country (Spain, Argentina, Colombia, and Mexico) randomized controlled trial (RCT) that will make it possible to study the generalization of the results in different Spanish-speaking students. Third, we are comparing the results with an active control, a rigorous Healthy Lifestyle program developed in Spain and characterized by the promotion of habits of physical health, diet, and sleep, that although outcomes analyses are in progress, preliminary data show acceptance and effectiveness of this lowintensity internet program to reduce the symptoms of depression [93]. However, this study has some limitations: first, dropout rates are expected to be high, as reported in previous research [144, 145]. For this reason, dropout rates have been taken into account in the calculation of the sample size. Second, Internet-based interventions for mental health also raise some ethical issues with regard to the exchange of data between Europe and America. For this reason, international guidelines will be followed to address these concerns [146, 147], as well as all aspects of Personal Data Protection under existing European legislation in compliance with General Data Protection Regulation 2016/679.

We consider that this study will provide future lines of research that will strengthen the implementation of these interventions. Little is known about the potential for cultural adaptation and the efficacy of interventions for mental disorders in low- and middle-income countries [148]. According to World Bank data, Colombia 
and Mexico are considered upper-middle-income countries and Argentina is a high-income country. However, the WHO includes them in America region, where the prevalence of mental disorders is higher than in the European region, but this variation may be due to the fact that many people have both conditions (comorbidity) and to the relatively larger populations between these two regions [5]. These data suggest the importance of prioritizing the prevention and treatment of mental disorders globally in both developing and developed regions [6].

An important aspect is that CORE and HLP have been developed in Europe and adapted to be implemented in the Latin-American countries. Language is an advantage that can favour accessibility to Spanish-speaking countries, and empirical evidence indicates that the advantages of interventions administered through the Internet can facilitate access to this population to promote mental health worldwide. Data from a systematic review indicate that, although there are few studies examining the effect of online interventions in low-income countries, the effectiveness of these online interventions in highincome countries and the current increase in Internet access should be taken into account. Moreover, these interventions may help to reduce the "mental health gap" in providing low-cost, more widely distributed mental health care [149]. In addition, CORE includes intervention strategies that have been found to be useful for improving resilience, and HLP includes psycho-educational components to prevent depressive symptoms. Therefore, both programs are expected to show more effectiveness than the Waiting List control group in Spanish-speaking countries.

In addition, this study will provide information regarding the possibilities of implement interventions designed in developed countries, in other countries or situations. The study will provide information about participant's acceptability and satisfaction with the intervention,

Finally, this protocol aims to increase access to and acceptance of Internet-based interventions, overcoming current mental health barriers in high-, middle-, and low-income countries, in order to implement and establish a comprehensive model of mental health promotion in Spanish-speaking countries in Europe and America.

\section{Trial status}

Recruitment for this study began in June 2019. It is currently in progress.

\section{Abbreviations}

CORE: Unguided internet-based resilience intervention; HLP: Healthy lifestyle program; WL: Waiting list control; CMHD: Common Mental Health Disorders

Acknowledgements

N/A

\section{Authors' contributions}

$A P G, R H, R B, A G P$ and $C B$ designed the study. CC, GLF, DML, LCG, LCT, and $L A B$ contributed significantly to the study design. $A P G, R H$, and $C B$ wrote the first draft of the manuscript. $A P G, R H, R B, A G P$ and $C B$ revised the manuscript and completed the final draft. All authors contributed feedback, read, and approved the final manuscript.

\section{Funding}

This work is supported by the European Union's Horizon 2020 Research and Innovation Programme, number 634757-ICARE and CIBEROBN, an initiative of the ISCIII (ISC III CB06 03/0052). This work is supported by the Marie Curie EFST AffecTech Project, approved at call H2020 - MSCA - ITN - 2016.

\section{Availability of data and materials}

Data will be available once the trial is finished under request.

\section{Ethics approval and consent to participate}

The research project was approved by the Ethics Committee of Jaume I University, Spain, with file number 24/2018 on 29 October 2018. All participants must give their written consent to participate.

\section{Consent for publication}

Not applicable in this study.

\section{Competing interests}

The authors declare that they have no competing interests.

\section{Author details}

${ }^{1}$ Universitat Jaume I, Castellón, Spain. ${ }^{2}$ CIBER of Physiopathology of Obesity and Nutrition (CB06/03) Instituto Salud Carlos III, Madrid, Spain. ${ }^{3}$ Universidad de Valencia, Av. Blasco Ibañez, 21, 46021 Valencia, Spain. ${ }^{4}$ Universidad Nacional de Mar del Plata, Mar del Plata, Argentina. ${ }^{5}$ Universidad de Buenos Aires, Buenos Aires, Argentina. ${ }^{6}$ Universidad Popular del Cesar, Valledupar, Colombia. ${ }^{7}$ Universidad Politécnica de Tecámac, Tecámac de Felipe Villanueva, Mexico.

Received: 15 September 2019 Accepted: 6 March 2020

Published online: 05 April 2020

\section{References}

1. World Health Organization. Mental health atlas 2017. Geneva; 2018. Available from: http://www.who.int/mental_health/evidence/atlas/mental_ health_atlas_2017/en/.

2. World Health Organization. Mental health atlas 2014. Geneva; 2015 [cited 2018 May 21]. Available from: http://www.who.int/mental_health/.

3. Organización Panamericana de la Salud. Depresión y otros trastornos mentales comunes. Estimaciones sanitarias mundiales. Washington, D.C; 2017

4. Mihalopoulos C, Vos T, Pirkis J, Carter R. The economic analysis of prevention in mental health programs. Annu Rev Clin Psychol. 2011;7(1): 169-201.

5. Organización Panamericana de la Salud. La carga de los trastornos mentales en la Región de las Américas, 2018. Organización Mundial de la Salud Oficina Regional para las Américas. Washington, D.C; 2018 [cited 2019 Jul 11]. 1-50 p. Available from: http://iris.paho.org/xmlui/bitstream/handle/123456789/49578/ 9789275320280_spa.pdf?sequence=9\&isAllowed=y.

6. Whiteford HA, Degenhardt L, Rehm J, Baxter AJ, Ferrari AJ, Erskine HE, et al. Global burden of disease attributable to mental and substance use disorders: Findings from the Global Burden of Disease Study 2010. Lancet. 2013;382(9904):1575-86.

7. World Health Organization. WHO | Mental health action plan 2013-2020 [Internet]. WHO Library. World Health Organization; 2013 [cited 2019 Jul 15]. Available from: https://www.who.int/mental_health/publications/action_plan/en/.

8. Kessler RC, Angermeyer M, Anthony JC, de Graaf R, Demyttenaere K, Gasquet I, et al. Lifetime prevalence and age-of-onset distributions of mental disorders in the World Health Organization ' s. World Psychiatry. 2007;6:168-76 2007;6(October):168-76.

9. Kessler RC, Berglund P, Demler O, Jin R, Merikangas KR, Walters EE. Lifetime prevalence and age-of-onset distributions of DSM-IV disorders in the National Comorbidity Survey Replication. Arch Gen Psychiatry. 2005;62(6):593. 
10. Auerbach RP, Alonso J, Axinn WG, Cuijpers P, Ebert DD, Green JG, et al. Mental disorders among college students in the World Health Organization world mental health surveys. Psychol Med. 2016;46(14):2955-70.

11. Merikangas KR, Nakamura EF, Kessler RC. Epidemiology of mental disorders in children and adolescents. Dialogues Clin Neurosci. 2009;11(1):7-20.

12. Ibrahim AK, Kelly SJ, Adams CE, Glazebrook C. A systematic review of studies of depression prevalence in university students. J Psychiatr Res. 2013;47(3):391-400.

13. Cuijpers $P$, Cristea IA, Ebert DD, Koot HM, Auerbach RP, Bruffaerts R, et al. Psychological treatment of depression in college students: a metaanalysis. Depress Anxiety. 2016;33(5):400-14.

14. Bayram N, Bilgel N. The prevalence and socio-demographic correlations of depression, anxiety and stress among a group of university students. Soc Psychiatry Psychiatr Epidemiol. 2008;43(8):667-72.

15. Adlaf EM, Gliksman L, Demers A, Newton-Taylor B. The prevalence of elevated psychological distress among Canadian undergraduates: findings from the 1998 Canadian campus survey. J Am Coll Health Assoc. 2001;50(2): $67-72$.

16. Cooke R, Bewick BM, Barkham M, Bradley M, Audin K. Measuring, monitoring and managing the psychological well-being of first year university students. Br J Guid Counc. 2006;34(4):505-17.

17. Nimh. Depression and College Students. [cited 2019 Jul 11]. Available from: https://infocenter.nimh.nih.gov/pubstatic/NIH.12-4266/NIH 12-4266.pdf.

18. Vaez M, Laflamme L. Experienced stress, psychological symptoms, self-rated health and academic achievement: a longitudinal study of swedish university students. Soc Behav Personal Int J. 2008;36(2):183-96.

19. Whitton SW, Whisman MA. Relationship satisfaction instability and depression. J Fam Psychol. 2010 Dec;24(6):791-4.

20. Hysenbegasi A, Hass SL, Rowland CR. The impact of depression on the academic productivity of university students. J Ment Health Policy Econ. 2005;8(3):145-51.

21. Fergusson DM, Woodward $\sqcup$. Mental health, educational, and social role outcomes of adolescents with depression. Arch Gen Psychiatry. 2002;59(3):225-31.

22. Harvey SB, Glozier N, Henderson M, Allaway S, Litchfield P, Holland-Elliott K, et al. Depression and work performance: an ecological study using webbased screening. Occup Med (Chic III). 2011;61(3):209-11.

23. Ribeiro IJS, Pereira R, Freire IV, de Oliveira BG, Casotti CA, Boery EN. Stress and quality of life Among University students: a systematic literature review. Heal Prof Educ. 2018;4(2):70-7.

24. Dray J, Bowman J, Campbell E, Freund M, Hodder R, Wolfenden L, et al. Effectiveness of a pragmatic school-based universal intervention targeting student resilience protective factors in reducing mental health problems in adolescents. J Adolesc. 2017;57:74-89.

25. Stallman HM. Psychological distress in university students: a comparison with general population data. Aust Psychol. 2010;45(4):249-57.

26. Huang J, Nigatu YT, Smail-Crevier R, Zhang X, Wang J. Interventions for common mental health problems among university and college students: A systematic review and meta-analysis of randomized controlled trials. J Psychiatric Res. 2018;107:1-10.

27. Hjemdal O, Vogel PA, Solem S, Hagen K, Stiles TC. The relationship between resilience and levels of anxiety, depression, and obsessive-compulsive symptoms in adolescents. Clin Psychol Psychother. 2011;18(4):314-21.

28. Minnard CV. A strong building: Foundation of Protective Factors in schools. Child Sch. 2002;24(4):233-46.

29. Fergus S, Zimmerman MA. Adolecent resilience: a framework for understanding healthy development in the face of risk. Annu Rev Public Health. 2005;26(1):399-419.

30. García del Castillo JA, García del Castillo-López Á, López-Sánchez C, Dias PC. Conceptualización teórica de la resiliencia psicosocial y su relación con la salud. Vol. 16, Health and Addictions. 2016.

31. Bowes L, Jaffee SR. Biology, Genes, and Resilience: Toward a Multidisciplinary Approach. Trauma Violence Abuse. 2013;14:195-208.

32. Stallard P, Buck R. Preventing depression and promoting resilience: feasibility study of a school-based cognitive-behavioural intervention. $\mathrm{Br} \mathrm{J}$ Psychiatry. 2013;202(s54):s18-23.

33. Davydov DM, Stewart R, Ritchie K, Chaudieu I. Resilience and mental health. Clin Psychol Rev. 2010;30(5):479-95

34. Gillham JE, Reivich KJ, Freres DR, Chaplin TM, Shatté AJ, Samuels B, et al. School-based prevention of depressive symptoms: a randomized controlled study of the effectiveness and specificity of the penn resiliency program. J Consult Clin Psychol. 2007;75(1):9-19.
35. Luthar SS, Cicchetti D, Becker B. The construct of resilience: a critical evaluation and guidelines for future work. Child Dev. 2000;71(3):543-62.

36. Galante J, Dufour G, Benton A, Howarth E, Vainre M, Croudace TJ, et al. Protocol for the mindful student study: a randomised controlled trial of the provision of a mindfulness intervention to support university students' wellbeing and resilience to stress. BMJ Open. 2016;6(11):e012300.

37. Joyce S, Shand F, Tighe J, Laurent SJ, Bryant RA, Harvey SB. Road to resilience: a systematic review and meta-analysis of resilience training programmes and interventions. BMJ Open. 2018;8(6):e017858.

38. Afifi TD, Merrill AF, Davis S. The theory of resilience and relational load. Pers Relatsh. 2016;23(4):663-83.

39. Steinhardt $M$, Dolbier $C$. Evaluation of a resilience intervention to enhance coping strategies and protective factors and decrease symptomatology. J Am Coll Heal. 2008;56(4):445-53.

40. Burton NW, Pakenham Kl, Brown WJ. Evaluating the effectiveness of psychosocial resilience training for heart health, and the added value of promoting physical activity: a cluster randomized trial of the READY program. BMC Public Health. 2009;9(1):427.

41. Lee JH, Nam SK, Kim AR, Kim B, Lee MY, Lee SM. Resilience: a meta-analytic approach. J Couns Dev. 2013;91(3):269-79.

42. Helmreich I, Kunzler A, Chmitorz A, König J, Binder $H$, Wessa M, et al. Psychological interventions for resilience enhancement in adults. Cochrane Database Syst Rev. 2017;2 2017(2).

43. Leppin AL, Bora PR, Tilburt JC, Gionfriddo MR, Zeballos-Palacios C, Dulohery MM, et al. The Efficacy of Resiliency Training Programs: A Systematic Review and MetaAnalysis of Randomized Trials. PLoS One. 2014;9(10):e111420.

44. Macedo T, Wilheim L, Gonçalves R, Coutinho ESF, Vilete L, Figueira I, et al. Building resilience for future adversity: a systematic review of interventions in non-clinical samples of adults. BMC Psychiatry. 2014 Dec 14;14(1):227.

45. García-Herrera Pérez BJ, Nogueras Monillas E, Muñoz Cobos F, Morales Asencio J. Guía de Práctica Clínica para el tratamiento de la depresión en Atención Primaria. Distrito Sanitario Málaga-UGC Salud Mental Hospital Regional Universitario "Carlos Haya," editor. Málaga; 2001.

46. The National Institute for Health and Care Excellence. The NICE Guideline on the Treatment and Depression the Treatment and Management of Depression [Internet]. NICE guidelines [CG90]. 2009. 1-592 p. Available from: http://www.ncbi.nlm.nih.gov/books/NBK55364/.

47. Nieuwsma JA, Trivedi RB, McDuffie J, Kronish I, Benjamin D, Williams JW. Brief psychotherapy for depression: a systematic review and meta-analysis. Int J Psychiatry Med. 2012;43(2):129-51.

48. Castro A, García-Palacios A, García-Campayo J, Mayoral F, Botella C, GarcíaHerrera JM, et al. Efficacy of low-intensity psychological intervention applied by ICTs for the treatment of depression in primary care: a controlled trial. BMC Psychiatry. 2015;15(1):106.

49. Gallardo-Escudero A, Muñoz Alférez MJ, María E, Del Pozo P, Aliaga IL. La etapa universitaria no favorece el estilo de vida saludable en lasestudiantes granadinas. Nutr HospNutr Hosp. 2015;31(2):975-979.

50. Rodríguez F, Palma X, Romo Á, Escobar D, Aragú B, Espinoza L, et al. Hábitos alimentarios, actividad física y nivel socioeconómico enestudiantes universitarios de Chile. Nutr HospNutr Hosp. 2013;28(2):447-455.

51. Sánchez-Ojeda MA, De Luna-Bertos E. Hábitos de vida saludable en la población universitaria. Nutr Hosp. 2015;31(5):1910-9.

52. Kazdin AE. Technology-based interventions and reducing the burdens of mental illness: perspectives and comments on the special series. Cogn Behav Pract. 2015;22(3):359-66.

53. Kazdin AE, Rabbitt SM. Novel models for delivering mental health services and reducing the burdens of mental illness. Clin Psychol Sci. 2013;1(2):170-91.

54. Kazdin AE, Blase SL. Rebooting psychotherapy research and practice to reduce the burden of mental illness. Perspect Psychol Sci. 2011;6(1):21-37.

55. Christensen $\mathrm{H}$, Hickie IB. Using e-health applications to deliver new mental health services. Med J Aust. 2010;192(11 Suppl):S53-6.

56. Eurostats. Digital economy and society statistics - households and individuals Statistics Explained. 2018 [cited 2019 Jul 15]. Available from: https://ec.europa.eu/eurostat/statistics-explained/index.php/Digital economy_and_society_statistics_-_households_and_individuals.

57. Rojas EF, Poveda L. Estado de la banda ancha en Ámerica Latina y el Caribe. 2017. Santiago; 2018 [cited 2019 Jul 15]. Available from: https://repositorio. cepal.org/bitstream/handle/11362/43365/1/S1800083_es.pdf.

58. Baños RM, Etchemendy E, Mira A, Riva G, Gaggioli A, Botella C. Online positive interventions to promote well-being and resilience in the adolescent population: a narrative review. Front Psychiatry. 2017;8:10. 
59. Day V, McGrath PJ, Wojtowicz M. Internet-based guided self-help for university students with anxiety, depression and stress: a randomized controlled clinical trial. Behav Res Ther. 2013;51(7):344-51.

60. Räsänen $\mathrm{P}$, Lappalainen P, Muotka J, Tolvanen A, Lappalainen R. An online guided ACT intervention for enhancing the psychological wellbeing of university students: a randomized controlled clinical trial. Behav Res Ther. 2016;78:30-42

61. Becker TD, Torous JB. Recent developments in digital mental health interventions for college and university students. Curr Treat Options Psychiatry. 2019;6(3):210-20.

62. Ebert DD, Zarski A-C, Christensen H, Stikkelbroek Y, Cuijpers P, Berking M, et al. Internet and computer-based cognitive behavioral therapy for anxiety and depression in youth: a meta-analysis of randomized controlled outcome trials. PLoS One. 2015;10(3):e0119895.

63. Herrero R, Mira A, Cormo G, Etchemendy E, Baños R, García-Palacios A, et al. An internet based intervention for improving resilience and coping strategies in university students: study protocol for a randomized controlled trial. Internet Interv. 2019;16:43-51.

64. Rose RD, Buckey JC, Zbozinek TD, Motivala SJ, Glenn DE, Cartreine JA, et al. A randomized controlled trial of a self-guided, multimedia, stressmanagement and resilience training program. Behav Res Ther. 2013;51(2):106-112.

65. Berger T, Hämmerli K, Gubser N, Andersson G, Caspar F. Internet-based treatment of depression: a randomized controlled trial comparing guided with unguided self-help. Cogn Behav Ther. 2011;40(4):251-66.

66. Andrews G, Cuijpers P, Craske MG, McEvoy P, Titov N. Computer therapy for the anxiety and depressive disorders is effective, acceptable and practical health care: a meta-analysis. PLoS One. 2010;5(10):e13196.

67. Botella C, Mira A, Herrero R, García-palacios A. Un programa de intervención auto-aplicado a través de Internet para el tratamiento de la depresión: "Sonreír es divertido.". Aloma Rev Psicol Ciències l'Educació i l'Esport. 2015;33(2):39-48.

68. Montero-Marín J, Araya R, Pérez-Yus MC, Mayoral F, Gili M, Botella C, et al. An internet-based intervention for depression in primary Care in Spain: a randomized controlled trial. J Med Internet Res. 2016;18(8):e231.

69. Ashford MT, Olander EK, Ayers S. Computer- or web-based interventions for perinatal mental health: a systematic review. J Affect Disord. 2016;197:134-46.

70. Griffiths KM, Christensen $\mathrm{H}$. Internet-based mental health programs: a powerful tool in the rural medical kit. Aust J Rural Health. 2007;15(2):81-7.

71. Hayward L, MacGregor AD, Peck DF, Wilkes P. The feasibility and effectiveness of computer-guided CBT (FearFighter) in a rural area. Behav Cogn Psychother. 2007;35(4):409-19.

72. Kaltenthaler E, Brazier J, De Nigris E, Tumur I, Ferriter M, Beverley C, et al. Computerised cognitive behaviour therapy for depression and anxiety update: a systematic review and economic evaluation. Health Technol Assess (Rockv). 2006;10(33):iii xi-xiv, 1-168.

73. Mitchell J, Vella-Brodrick D, Klein B. Positive psychology and the internet: a mental health opportunity. E-J Appl Psychol 2010 30;6(2):30-41.

74. Muñoz RF. Using evidence-based internet interventions to reduce health disparities worldwide. J Med Internet Res. 2010;12(5):e60.

75. Heber E, Ebert DD, Lehr D, Cuijpers P, Berking M, Nobis S, et al. The benefit of web- and computer-based interventions for stress: a systematic review and meta-analysis. J Med Internet Res. 2017;19(2):e32

76. Sander L, Rausch L, Baumeister H. Effectiveness of internet-based interventions for the prevention of mental disorders: a systematic review and meta-analysis. JMIR Ment Heal. 2016;3(3):e38.

77. Díaz-García A, González-Robles A, Fernández-Álvarez J, García-Palacios A, Baños RM, Botella C. Efficacy of a Transdiagnostic internet-based treatment for emotional disorders with a specific component to address positive affect: study protocol for a randomized controlled trial. BMC Psychiatry. 2017;17(1):145.

78. Bernal G, Domenech Rodríguez MM. Cultural adaptation in context: Psychotherapy as a historical account of adaptations. In Bernal G, DomenechRodríguez MM, editors Cultural adaptations: Tools for evidencebased practice with diverse populations. Whashington: American Psychological Association. 2012:3-22

79. Chowdhary N, Jotheeswaran AT, Nadkarni A, Hollon SD, King M, Jordans MJD, et al. The methods and outcomes of cultural adaptations of psychological treatments for depressive disorders: a systematic review. Psychol Med. 2014;44(6):1131-46.

80. Chu J, Leino A. Advancement in the maturing science of cultural adaptations of evidence-based interventions. J Consult Clin Psychol. 2017; 85(1):45-57.
81. Helms JE. An examination of the evidence in culturally adapted evidencebased or empirically supported interventions. Transcult Psychiatry. $2015 \mathrm{Apr}$ [cited 2020 Jan 29];52(2):174-97. Available from: http://www.ncbi.nlm.nih. gov/pubmed/25534401.

82. Salamanca-Sanabria A, Richards D, Timulak L. Adapting an internetdelivered intervention for depression for a Colombian college student population: an illustration of an integrative empirical approach. Internet Interv. 2019;15(October 2018):76-86 Available from: https://doi.org/10. 1016/j.invent.2018.11.005.

83. Hall GCN, Ibaraki AY, Huang ER, Marti CN, Stice E. A meta-analysis of cultural adaptations of psychological interventions. Behav Ther. 2016;47(6):993-1014.

84. Vally Z, Maggott C. Evaluating the Outcome of Cultural Adaptations of Cognitive-Behavioural Therapy for Adult Depression: a Meta-Analysis. Int J Advanc Counselling. 2015;37(4):293-304.

85. Arjadi R, Nauta MH, Chowdhary $\mathrm{N}$, et al. A systematic review of online interventions for mental health in low and middle income countries: a neglected field. Glob Ment Health (Camb). 2015;2:e12. https://doi.org/10. 1017/gmh.2015.10.

86. Ryff CD. Happiness is everything, or is it? Explorations on the meaning of psychological well-being. J Pers Soc Psychol. 1989;57(6):1069-81.

87. van Dierendonck D. The construct validity of Ryff's scales of psychological well-being and its extension with spiritual well-being. Pers Individ Dif. 2004 Feb;36(3):629-43.

88. Díaz D, Rodríguez-Carvajal R, Blanco A, Moreno-Jiménez B, Gallardo I, Valle C, et al. Adaptación española de las escalas de bienestar psicológico de Ryff. Psicothema. 2006;18(3):572-7.

89. Watson D, Clark LA, Tellegen A. Development and validation of brief measures of positive and negative affect: the PANAS scales. J Pers Soc Psychol. 1988;54(6):1063-70.

90. Cohen J. Statistical power analysis for the behavioral sciences. 2nd ed. Hillsdale: Lawrence Earlbaum Associates. Lawrence Earlbaum Associates; 1988. 286 p.

91. Muller KE, Edwards LJ, Simpson SL, Taylor DJ. Statistical tests with accurate size and power for balanced linear mixed models. Stat Med. 2007;26(19): 3639.

92. Ryff CD. Psychological well-being revisited: advances in the science and practice of Eudaimonia. Psychother Psychosom. 2014;83(1):10-28.

93. Castro A, García-Palacios A, García-Campayo J, Mayoral F, Botella C, GarcíaHerrera JM, et al. Efficacy of low-intensity psychological intervention applied by ICTs for the treatment of depression in primary care: A controlled trial. BMC Psychiatry. 2015;15(1):1-10 Available from: ???.

94. Monreal-Bartolomé A, Barceló-Soler A, Castro A, Pérez-Ara MÁ, Gili M, Mayoral F, et al. Efficacy of a blended low-intensity internet-delivered psychological programme in patients with multimorbidity in primary care: study protocol for a randomized controlled trial. BMC Psychiatry [Internet] 2019 Dec 11 [cited 2020 Feb 1];19(1):66. Available from: https:// bmcpsychiatry.biomedcentral.com/articles/10.1186/s12888-019-2037-3.

95. Gómez-Juanes R, Roca M, Gili M, García-Campayo J, García-Toro M. Estilo de vida saludable: un factor de protección minusvalorado frente a la depresión. Psiquiatr Biológica. 2017;24(3):97-105.

96. Connor KM, Davidson JRT. Development of a new resilience scale: The Connor-Davidson Resilience Scale (CD-RISC). Depress Anxiety. 2003;18(2):76.

97. Yu X, Zhang J. Factor analysis and psychometric evaluation of the ConnorDavidson resilience scale (CD-RISC) with Chinese people. Soc Behav Personal Int J. 2007;35(1):19-30.

98. Singh K, Yu X. Psychometric evaluation of the Connor-Davidson resilience scale (CD-RISC) in a sample of Indian students. J Psychol. 2010;1(1):23-30.

99. Crespo M, Fernandez-Lansac V, Soberón C. Adaptación Española de la "Escala de Resiliencia de Connor-Davidson" (CD-RISC) en situaciones de estrés crónico. Behav Psychol. 2014;22:219-38 Available from: https://www. researchgate.net/publication/260882710_Spanish_Version_of_the_CD-RISC_ Resilience_Scale_for_Chronic_Stress_Situations.

100. Manzano-García G, Ayala Calvo JC. Propiedades psicométricas de la Escala de Resiliencia de Connor-Davidson en una muestra de emprendedores españoles. Psicothema. 2013;25(2):245-51.

101. Sandín B, Chorot P, Lostao L, Joiner TE, Santed MA, Valiente RM. Escalas PANAS de afecto positivo y negativo: validación factorial y convergencia transcultural. Psicothema. 1999;11:37-51.

102. Feldman GC, Joormann J, Johnson SL. Responses to positive affect: a selfreport measure of rumination and dampening. Cognit Ther Res. 2008 Aug 1;32(4):507-25. 
103. Johnson $\mathrm{SL}$, Jones $\mathrm{S}$. Cognitive correlates of mania risk: are responses to success, positive moods, and manic symptoms distinct or overlapping? Clin Psychol. 2009;65(9):891-905.

104. Botella C, Molinari G, Fernández-Álvarez J, Guillén V, García-Palacios A, Baños $\mathrm{RM}$, et al. Development and validation of the openness to the future scale: a prospective protective factor. Health Qual Life Outcomes. 2018;16(1):72.

105. Kroenke K, Spitzer RL, Williams JBW. The PHQ-9. J Gen Intern Med. 2001; 16(9):606-13.

106. Wittkampf KA, Naeije L, Schene AH, Huyser J, van Weert HC. Diagnostic accuracy of the mood module of the patient health questionnaire: a systematic review. Gen Hosp Psychiatry. 2007;29(5):388-95.

107. Bentley KH, Gallagher MW, Carl JR, Barlow DH. Development and validation of the overall depression severity and impairment scale. Psychol Assess. 2014;26(3):815-30.

108. Osma J, Quilez-Orden A, Suso-Ribera C, Peris-Baquero O, Norman SB, Bentley $\mathrm{KH}$, et al. Psychometric properties and validation of the Spanish versions of the overall anxiety and depression severity and impairment scales. J Affect Disord. 2019;252(March):9-18. Available from: https://doi.org/ 10.1016/j.jad.2019.03.063.

109. Norman SB, Hami Cissell S, Means-Christensen AJ, Stein MB. Development and validation of an overall anxiety severity and impairment scale (OASIS). Depress Anxiety. 2006;23(4):245-9.

110. González-Robles A, Mira A, Miguel C, Molinari G, Díaz-García A, García-Palacios $A$, et al. A brief online transdiagnostic measure: Psychometric properties of the Overall Anxiety Severity and Impairment Scale (OASIS) among Spanish patients with emotional disorders. PLoS One. 2018;13(11):e0206516.

111. Spitzer RL, Kroenke K, Williams JBW, Löwe B. A brief measure for assessing generalized anxiety disorder. Arch Intern Med. 2006;166(10):1092.

112. Löwe B, Decker $O$, Müller S, Brähler $E$, Schellberg D, Herzog W, et al. Validation and standardization of the generalized anxiety disorder screener (GAD-7) in the general population. Med Care. 2008:46(3):266-74.

113. García-Campayo J, Zamorano E, Ruiz MA, Pardo A, Pérez-Páramo M, López-Gómez $\checkmark$, et al. Cultural adaptation into Spanish of the generalized anxiety disorder-7 (GAD-7) scale as a screening tool. Health Qual Life Outcomes. 2010;8:1-11.

114. Solis J, Cohen S, Kamarck T, Mermelstein R. A global measure of perceived stress. J Health Soc Behav. 1983;24:385-96.

115. Cohen S, Williamson GM. Perceived stress in a probability sample of the US. In: Spacapam S, Oskamp S, editors. The Social Psychology of Health: Claremont Symposium on Applied Social Psychology; 1988. p. 31-67.

116. Mitchell AM, Crane PA, Kim Y. Perceived stress in survivors of suicide: psychometric properties of the perceived stress scale. Res Nurs Health. 2008;31(6):576-85.

117. Raes F, Pommier E, Neff KD, Van Gucht D. Construction and factorial validation of a short form of the self-compassion scale. Clin Psychol Psychother Clin Psychol Psychother. 2011;18:250-5.

118. Neff KD. The development and validation of a scale to measure selfcompassion. Self Identity. 2003:2(3):223-50.

119. Rammstedt B, John OP. Measuring personality in one minute or less: a 10item short version of the big five inventory in English and German. J Res Pers. 2007;41(1):203-12.

120. John OP, Srivastava SP. The Big-five Trait Taxonomy: History, Measurement, and Theoretical Perspectives. Guilford, editor. New York; 1999

121. Devilly GJ, Borkovec TD. Psychometric properties of the credibility/ expectancy questionnaire. J Behav Ther Exp Psychiatry. 2000;31(2):73-86.

122. Attkisson CC, Greenfield TK. Client satisfaction Questionnaire-8 and service satisfaction Scale-30. In: The Use of Psychological Testing for Treatment Planning and Outcome Assessment; 1994. p. 402-20.

123. Larsen DL, Attkisson CC, Hargreaves WA, Nguyen TD. Assessment of client/ patient satisfaction: development of a general scale. Eval Program Plann. 1979;2(3):197-207

124. Attkisson CC, Zwick R. The client satisfaction questionnaire: psychometric properties and correlations with service utilization and psychotherapy outcome. Eval Program Plann. 1982;5(3):233-7.

125. Roberts RE, Attkisson CC. Assessing client satisfaction among hispanics. Eval Program Plann. 1983;6(3-4):401-13.

126. Kiluk BD, Serafini K, Frankforter T, Nich C, Carroll KM. Only connect: the working alliance in computer-based cognitive behavioral therapy. Behav Res Ther. 2014:63:139-46.

127. Schulz KF, Altman DG, Moher D. CONSORT 2010 statement: updated guidelines for reporting parallel group randomised trials. BMC Med. 2010;24:8.

128. Gueorguieva R, Krystal JH. Move over ANOVA: Progress in Analyzing Repeated-Measures Data and Its Reflection in Papers Published in the Archives of General Psychiatry. Arch Gen Psychiatry. 2004;61:310-7.
129. Wright CC, Sim J. Intention-to-treat approach to data from randomized controlled trials: a sensitivity analysis. J Clin Epidemiol. 2003:56(9):833-42.

130. Ryff CD, Singer B. Psychological Weil-being: meaning, measurement, and implications for psychotherapy research. Psychother Psychosom. 1996;65(1):14-23.

131. Ryff CD, Love GD, Essex MJ, Singer B. Resilience in adulthood and later life. In: Handbook of aging and mental health. Boston: Springer US; 1998. p. 69-96.

132. Copeland W, Shanahan L, Costello EJ, Angold A. Cumulative prevalence of psychiatric disorders by young adulthood: a prospective cohort analysis from the Great Smoky Mountains study. J Am Acad Child Adolesc Psychiatry. 2011;50(3):252-61.

133. Calear AL, Christensen $\mathrm{H}$. Systematic review of school-based prevention and early intervention programs for depression. J Adolesc. 2010;33(3):429-38.

134. Cuijpers P, Driessen E, Hollon SD, van Oppen P, Barth J, Andersson G. The efficacy of non-directive supportive therapy for adult depression: a metaanalysis. Clin Psychol Rev. 2012:32(4):280-91.

135. van Zoonen K, Buntrock C, Ebert DD, Smit F, Reynolds CF, Beekman AT, et al. Preventing the onset of major depressive disorder: a meta-analytic review of psychological interventions. Int J Epidemiol. 2014;43(2):318-29.

136. Organización Panamericana de la Salud. Depresión y otros trastornos mentales comunes. Washington, D.C; 2017. Available from: http://iris.paho. org/xmlui/bitstream/handle/123456789/34006/PAHONMH17005-spa.pdf.

137. Organización Mundial de la Salud. Plan de acción sobre salud mental 20132020. Organ Mund la salud. 2013;54. Available from: http://apps.who.int/iris/ bitstream/10665/97488/1/9789243506029_spa.pdf.

138. Cuijpers P, Cristea IA, Ebert DD, Koot HM, Auerbach RP, Bruffaerts R, et al. Psychological treatment of depression in college students: A metaanalysis. Vol. 33, Depression and Anxiety. 2016. p. 400-14.

139. Stengård E, Appelqvist-Schmidlechner K. Mental health promotion in young people-an Investment for the Future [internet]. Copenhagen, Denmark; 2010 [cited 2019 Jul 16]. Available from: http://www.euro.who.int/pubrequest.

140. Hollon SD, Muñoz RF, Barlow DH, Beardslee WR, Bell CC, Bernal G, et al. Psychosocial intervention development for the prevention and treatment of depression: Promoting innovation and increasing access. Biological Psychiatry. 2002;52:610-30

141. New Freedom Commision on Mental Health. Achieving the promise: Transforming mental health care in America | Suicide Prevention Resource Center [Internet]. 2003 [cited 2020 Jan 24]. Available from: https://www.sprc.org/ resources-programs/achieving-promise-transforming-mental-health-care-america.

142. Barbato A, Vallarino M, Rapisarda F, Lora A, Caldas De Almeida M. EU compass for action on mental health and well-being. Access to mental health care in europe [Internet]. 2014 [cited 2018 May 21]. Available from: https://ec.europa. eu/health/sites/health/files/mental_health/docs/ev_20161006_co02_en.pdf.

143. Caldas de Almeida JM, Frasquilho D, Mateus P, Antunes A, Cardoso G, Silva $M$, et al. EU-Compass for action on mental health and wellbeing. Summary and analysis of key developments in member states and stakeholders [Internet]. 2017 [cited 2018 May 21]. Available from: https://ec.europa.eu/ health/sites/health/files/mental_health/docs/ev_20161006_co06_en.pdf.

144. van Ballegooijen W, Cuijpers P, van Straten A, Karyotaki E, Andersson G, Smit $J \mathrm{H}$, et al. Adherence to Internet-Based and Face-to-Face Cognitive Behavioural Therapy for Depression: A Meta-Analysis. PLoS One. 2014;9(7):e100674.

145. Spek V, Cuijpers P, Nyklícek I, Riper H, Keyzer J, Pop V. Internet-based cognitive behaviour therapy for symptoms of depression and anxiety: a meta-analysis. Psychol Med. 2007;37(03):319

146. Barak A, Klein B, Proudfoot JG. Defining internet-supported therapeutic interventions. Ann Behav Med. 2009:38(1):4-17.

147. Ritterband LM, Andersson G, Christensen HM, Carlbring P, Cuijpers P. Directions for the International Society for Research on internet interventions (ISRII). J Med Internet Res. 2006;8(3):e23.

148. Salamanca-Sanabria A, Richards D, Timulak L, Castro-Camacho L, MojicaPerilla M, Parra-Villa Y. Assessing the efficacy of a culturally adapted cognitive behavioural internet-delivered treatment for depression: protocol for a randomised controlled trial. BMC Psychiatry. 2018;18(1):53.

149. Arjadi R, Nauta MH, Chowdhary N, Bockting CLH. A systematic review of online interventions for mental health in low and middle income countries: a neglected field. Glob Ment Heal. 2015;2:e12.

\section{Publisher's Note}

Springer Nature remains neutral with regard to jurisdictional claims in published maps and institutional affiliations. 